\section{CREATING SPACE FOR PARTICIPATORY GOVERNANCE- A COMMUNITY BASED MONITORING APPROACH FOR ENSURING STATES ACCOUNTABILITY}

Tarang s Mishra, Leni S Chaudhuri. Narotam Sekhsaria Foundation, Mumbai, India

10.1136/bmjopen-2015-forum2015abstracts. 14

Background With more than half of the child population suffering from under nourishment in India, ${ }^{1}$ it merits the attention of a national calamity. The welfare has initiated several programmes and schemes to provide food and nutrition to the impoverished communities. The flagship program being Integrated Child Development Scheme (ICDS) which is one of the world's largest and unique programme for early childhood development. ${ }^{2}$ However, the program suffers majorly on account of quality and outreach. The most significant gap being lack of state accountability and community participation in planning and implementation of the services.

To address this gap The Narotam Sekhsaria Foundation initiated the Nutrition Rights Programme in six districts of Maharashtra to demonstrate a model which strivesto make nutrition services accountable and responsive through Community Based Monitoring and Action Approach (CBMA). This paper discusses the results achieved by the CBMA process

Objectives To study the role of community based monitoring mechanism in ensuring accountability and responsiveness of government services focusing on child development and nutrition.

Methods This project was implemented in six districts (rural and urban), covering in total 115 Anganwadi centers (village based health and nutrition centers). The process included multistakeholder monitoring committees at various levels; community-based data collection and filling of service report cards; organizing public hearings and periodic state level dialogues, with community-based planning focused on the corrective measures to be taken at each level.

The findings are based on formative analysis of primary data collected during CBMA process including indicators which aim to measure service availability and quality.
Result While the quantitative indicators showed marked improvement in the availability of growth monitoring services, utilization of Anganwadi services and health checkups, the process indicators reflect remarkable increase in public participation among beneficiaries.

Conclusion A system of partnership where community plays a lead role in planning and monitoring of services, can bring a sustainable change. 